\title{
Traction injury during minimally invasive harvesting of the saphenous vein is associated with impaired endothelial function
}

\author{
Richard C. Cook, MD \\ Christine M. Crowley, $\mathrm{PhD}^{\mathrm{b}}$ \\ Robert Hayden, MD ${ }^{\mathrm{a}}$ \\ Min Gao, PhD ${ }^{a}$ \\ Lynn Fedoruk, MDa
}

Samuel V. Lichtenstein, MD, $\mathrm{PhD}^{\mathrm{a}}$

Cornelis van Breemen, DVM, $\mathrm{PhD}^{\mathrm{b}}$
From the Departments of Cardiovascular Surgery $^{\mathrm{a}}$ and Pharmacology and Therapeutics, ${ }^{\text {b }}$ University of British Columbia, Vancouver, British Columbia, Canada.

Supported in part by the St Paul's Hospital Foundation and the British Columbia Heart and Stroke Foundation.

Read at the Twenty-eighth Annual Meeting of The Western Thoracic Surgical Association, Big Sky, Mont, June 19-22, 2002.

Received for publication July 10, 2002; revisions requested Sept 3, 2002; revisions received March 25, 2003; accepted for publication April 21, 2003.

Address for reprints: Richard C. Cook, MD, Division of Cardiovascular Surgery, University of British Columbia, \#314-700 West 10th Ave, Vancouver, British Columbia, Canada V5Z 4E5 (E-mail: residentcook@ hotmail.com).

J Thorac Cardiovasc Surg 2004;127:65-71 $0022-5223 / \$ 30.00$

Copyright () 2004 by The American Association for Thoracic Surgery

doi:10.1016/S0022-5223(03)01024-9
Objective: Many methods of minimally invasive surgical harvesting of the great saphenous vein have been developed because of the morbidity related to the long skin incision after traditional (open) great saphenous vein harvesting. One such method involves the use of multiple small incisions separated by $10-$ to $15-\mathrm{cm}$ skin bridges through which the saphenous vein is harvested. We hypothesized that this method of saphenous vein harvesting might subject the saphenous vein to considerable traction forces, resulting in impaired endothelial cell function.

Methods: Four-millimeter great saphenous vein segments were obtained from patients undergoing elective coronary artery bypass graft surgery. Group A (minimally invasive surgery) consisted of 23 rings from 20 patients (age, $65.8 \pm 11.1$ years, mean $\pm \mathrm{SD}$ ). Group B (open harvesting) consisted of 33 rings from 8 patients (age, $69.8 \pm 8.6$ years). All great saphenous vein segments were undistended and were used within 24 hours of harvesting. Isometric tension experiments were performed on each ring of the great saphenous vein by using a force-displacement transducer to measure the force of contraction in grams. Measurements included developed force after exposure to high-potassium depolarizing solution and 50 $\mu \mathrm{mol} / \mathrm{L}$ phenylephrine and decrease in force of contraction (relaxation) after exposure to 1 and $10 \mu \mathrm{mol} / \mathrm{L}$ acetylcholine.

Results: There were no differences between the minimally invasive surgery and open harvesting groups in their responses to high-potassium depolarizing solution or phenylephrine: high-potassium depolarizing solution, contractions of $4.26 \pm 0.72 \mathrm{~g}$ (mean \pm SEM) and $3.95 \pm 0.38 \mathrm{~g}$, respectively $(P=.70)$; phenylephrine, contractions of $3.49 \pm 0.63 \mathrm{~g}$ and $2.73 \pm 0.39 \mathrm{~g}$, respectively $(P=.41)$. There was no net relaxation in segments from the minimally invasive surgery group after exposure to 1.0 or $10 \mu \mathrm{mol} / \mathrm{L}$ acetylcholine. In contrast, rings from the open harvesting group demonstrated relaxation of $-0.41 \pm 0.07 \mathrm{~g}$ and $-0.32 \pm 0.09 \mathrm{~g}$ after exposure to 1.0 and $10 \mu \mathrm{mol} / \mathrm{L}$ acetylcholine, respectively.

Conclusions: In undistended saphenous vein segments isolated from patients undergoing minimally invasive surgical and open techniques of harvesting, there was no acetylcholine-mediated endothelium-dependent relaxation in the minimally invasive surgery group. Therefore harvesting of the great saphenous vein through multiple small incisions might result in endothelial dysfunction, possibly caused by traction injury. 


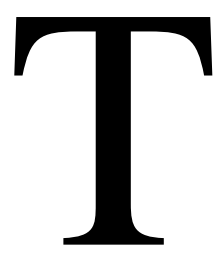

he saphenous vein (SV) remains one of the most commonly used conduits for coronary artery bypass graft (CABG) surgery. It has been well established that the traditional method for harvesting the great SV (GSV) through a long incision along the medial aspect of the lower extremity is associated with substantial morbidity in terms of wound infection, pain, and bleeding. ${ }^{1}$ The recent emphasis on minimally invasive surgical (MIS) techniques has lead to the development of numerous methods for MIS SV procurement. In addition to the cosmetic benefits of MIS harvesting of the GSV, several authors have demonstrated significant reductions in morbidity using endoscopic equipment or lighted retractors. ${ }^{1-3}$

Unfortunately, the equipment necessary for MIS procurement of the GSV is often expensive, with the added costs of nonreusable parts required for each patient. In Canada the economic constraints of a publicly funded health care system have slowed the adoption of MIS harvesting of the GSV with endoscopes or lighted retractors. In an effort to reduce the morbidity associated with the traditional method of GSV harvesting without incurring the increased costs associated with specialized equipment, one center in British Columbia (Royal Columbian Hospital) started harvesting the GSV through multiple small incisions separated by skin bridges using only standard unlighted retractors. Because an endoscope or lighted retractor was not used, visualization of the GSV under the skin bridges was often suboptimal; therefore traction was applied to the vein to expose it through one of the small incisions.

Fabricius and colleagues ${ }^{3}$ hypothesized that traction forces applied to the GSV during procurement of the vein might be detrimental to the structural and functional integrity of the GSV. Furthermore, it is now well established that impairment of biologic properties, such as endothelial cell function, stimulates myointimal proliferation, ${ }^{4}$ thereby affecting short- and long-term graft performance. ${ }^{5,6}$ In fact, the most problematic long-term complication of CABG surgery is the recurrence of coronary atherosclerotic disease, particularly in SV bypass grafts. The incidence of SV bypass graft occlusion is believed to be approximately $10 \%$ to $20 \%$ at 1 year and $50 \%$ at 10 years. ${ }^{7}$ Recent evidence from studies using intravascular ultrasonography has demonstrated that significant intimal thickening occurs by 1 year. $^{8}$

The effects of MIS techniques on the functional integrity of vein graft segments have been studied for some of the commercially available lighted retractors and endoscopic vein-harvesting methods. ${ }^{1-3,9,10}$ The reported methods did not involve substantial traction injury and did not result in impaired vein graft function. The purpose of this study was to determine whether MIS harvesting of the GSV without

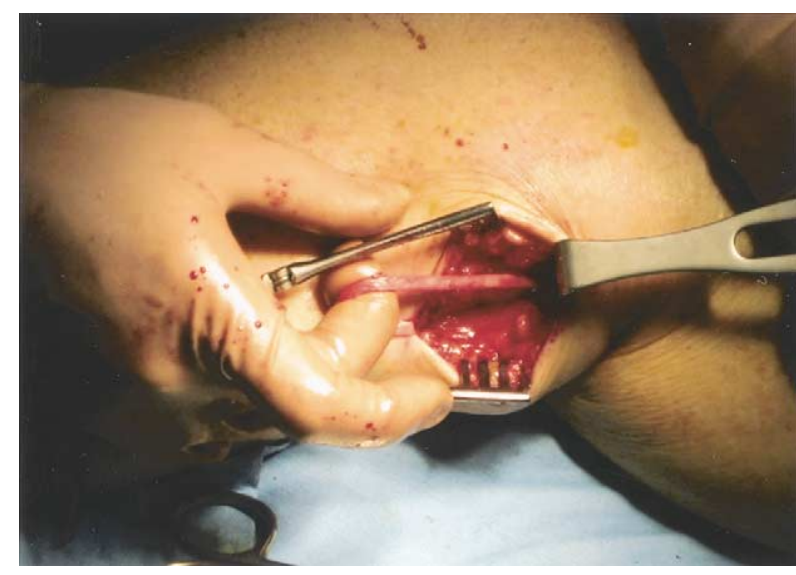

Figure 1. Operative photo of the MIS technique of SV harvest. Note that the SV is wrapped around the finger to expose it through a small incision in the leg. Only a self-retaining retractor and an unlighted handheld retractor are used for exposure.

the aid of a lighted retractor or endoscopic equipment causes impaired endothelial cell function.

\section{Methods}

Segments of the GSV were harvested from patients undergoing elective CABG surgery at St Paul's Hospital and the Royal Columbian Hospital, who were sampled from a population of elderly patients afflicted with isolated coronary artery disease in British Columbia, Canada. Institutional approval for the use of these tissues was obtained.

\section{Isolation at Royal Columbian Hospital (MIS Group)}

Group A (MIS) consisted of 23 rings from 20 patients (age, 65.8 \pm 11.1 years; mean \pm SEM). At Royal Columbian Hospital, GSV harvest was performed by using an MIS technique. Specifically, multiple small 8 - to $10-\mathrm{cm}$ incisions separated by $10-$ to $15-\mathrm{cm}$ skin bridges were made in lieu of the single long incision used in the open harvesting technique. The vein was isolated through the small incision sites, and an unlighted retractor was used to aid in the exposure of the GSV underneath the skin bridges. Tributaries were clipped and divided between clips. Traction was applied to the vein to gain exposure to some of the tributaries under the skin bridges (Figure 1).

\section{Isolation at St Paul's Hospital (Open Harvesting Group)}

Group B (open harvesting) consisted of 33 rings from 8 patients (age, $69.8 \pm 8.6$ years). The general procedure for isolating and preparing the vein for grafting at St Paul's Hospital can be described as the traditional open harvesting technique; that is, the vein is harvested from a single incision along the medial aspect of the lower extremity. In this procedure the GSV was isolated from surrounding connective tissues. The side branches were ligated with clips or silk ligatures and divided. Once the vein was completely freed from the areolar tissues, it was divided proximally and distally and placed in Plasma-Lyte solution. 


\section{Specimen Transport}

An undistended segment of the GSV was sectioned from the distal or proximal end as soon as the vein had been harvested and before preparation for grafting. Each specimen was placed in its own 50-mL centrifuge tube containing RPMI cell culture medium stored in a designated refrigerator located in the operating room core. The specimen was then transported to the laboratory in a cooler with ice for use within 24 hours of procurement. Each vial was carefully labeled with the identity of the specimen and the time it was placed in the vial. An addressograph label containing patient information, including age, sex, and hospital identification number, was also added to the vial for tracking purposes.

\section{Isometric Tension Experiments}

Samples of the GSV retrieved from the morning cases were used the same day. Those from the afternoon cases were stored in the refrigerator overnight. Excess adventitia and fat were removed from blood vessels in cold physiologic salt solution (PSS) and cut into rings $4 \mathrm{~mm}$ in length. Only GSV segments devoid of any obvious lesions were used in this study. Rings were excluded if control high-potassium depolarizing solution (high- $\mathrm{K}^{+}$) contractions were less than $0.5 \mathrm{~g}$.

Because it is now well established that vein segments studied after distention have little or no vasoconstrictive capacity and furthermore exhibit no vasodilatory response to acetylcholine $(\mathrm{ACh}),{ }^{6-8}$ only undistended segments of vein were used for this study.

Rings were mounted on pairs of stainless-steel metal hooks and placed in glass-jacketed tissue baths containing $10 \mathrm{~mL}$ of PSS solution ( $\mathrm{pH} 7.4$ ) warmed to $37^{\circ} \mathrm{C}$ and oxygenated with $100 \% \mathrm{O}_{2}$. One end was attached permanently to a tissue bath hook, and the other was connected with sutures to a force-displacement transducer (FT03E; Grass Instrument Division, Astro-Med, Inc). The output from force transducers was fed to analog signal ETH-400 amplifiers (CB Sciences). The voltage signals were converted to digital signals and recorded with both MacLab 8/s and PowerLab 8/s computer-based recorders on a Power Macintosh (7200/90) and a PC (Pentium $133 \mathrm{MHz}$, Trison), respectively. Chart recording software (ADInstruments) was used for data acquisition. Tissues were equilibrated under zero tension for 90 to 120 minutes, and the bathing medium was changed every 15 minutes. Passive tension was applied by stretching the ring 3 times over a 45 -minute period to overcome stress relaxation, such that a final resting tension of 2 to $2.5 \mathrm{~g}$ was achieved for the vein segment. Each stretch was preceded by a 15-minute wash. A resting tension of 2 to $2.5 \mathrm{~g}$ was the minimum stretch shown to produce maximum active tension in response to contractile stimuli.

\section{Experimental Protocol}

Contractile function. Isometric tension experiments were performed on each of the GSV rings. Rings were first challenged with 1 to 3 exposures to high- $\mathrm{K}^{+}$. Then the force of contraction was measured in response to phenylephyrine (PE), a commonly used contractile stimulus.

Endothelial cell function. Several methods of testing endothelial function have been developed. ${ }^{11} \mathrm{ACh}$, which stimulates the release of nitric oxide (NO), is the mediator of choice to test SV endothelial cell function. ${ }^{2,9}$ After a precontraction of the GSV ring
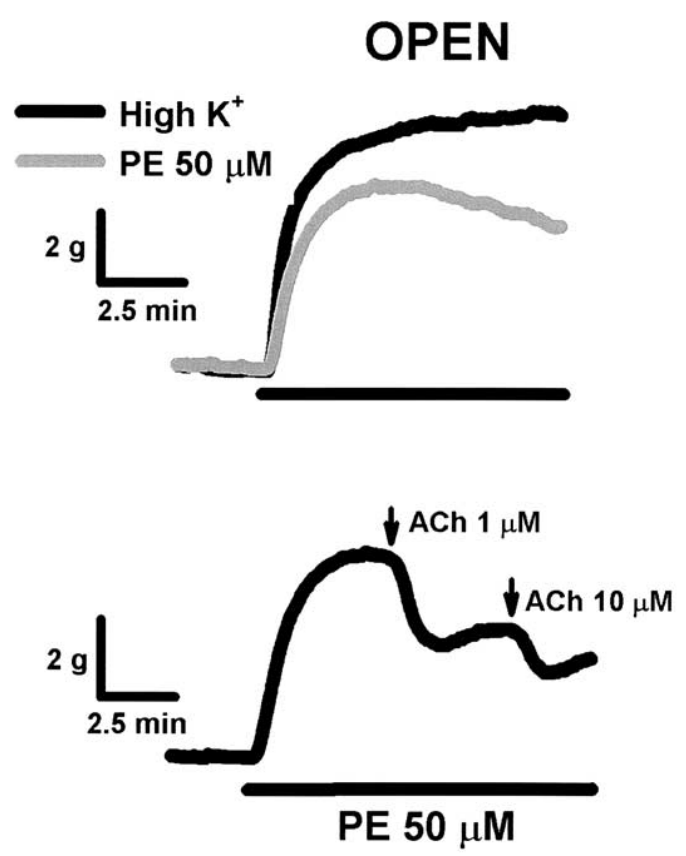

Figure 2. Sample tracing of contractile response to high- $\mathrm{K}^{+}$and $P E$ and relative relaxation in response to $A C h$ in a GSV ring from the open harvesting group. The upper panel shows force of contraction (in grams) over time (in minutes), with the normal contractile response to high- $\mathrm{K}^{+}$indicated by the solid black line and contractile response to $\mathrm{PE}$ indicated by the gray line. The lower panel shows normal 1 and $10 \mu \mathrm{mol} / \mathrm{L}$ ACh-mediated endothelium-dependent relaxations after precontraction with 50 $\mu \mathrm{mol} / \mathrm{L} \mathrm{PE}$ (addition of ACh is indicated by arrows).

with PE, ACh normally stimulates a decrease in tension or vasodilation. In the absence of normal endothelial function, there is no vasodilation; in fact, one might observe paradoxical vasoconstriction.

In this study endothelial cell function was tested by adding the vasodilator ACh to the peak of PE-precontracted rings in 2 high doses $(1$ and $10 \mu \mathrm{mol} / \mathrm{L})$. It should be noted that responses to ACh were corrected for the declining plateau phase with PE stimulation (Figure 2).

All stimuli remained in contact with the tissues for the duration of the responses.

\section{Data Analysis}

Off-line analysis was performed by using the Data Pad window in Chart. Data were imported into a Microsoft Excel spreadsheet. Statistical analysis was performed by using JMP software (SAS Institute, Inc). Responses were expressed as means \pm SEM. Patients were assigned to one of the 2 treatment groups (MIS vs open harvesting), and for each patient, a varying number of rings was investigated. There are 2 levels of variability: between patients and between rings within patients. The multilevel mixed effect model methods were used in the comparison of responses to high- $\mathrm{K}^{+}$or $\mathrm{PE}$ between the MIS and open harvesting groups and in the evaluation of net relaxations in segments for the 2 treatment groups separately to take the data structure into account. 


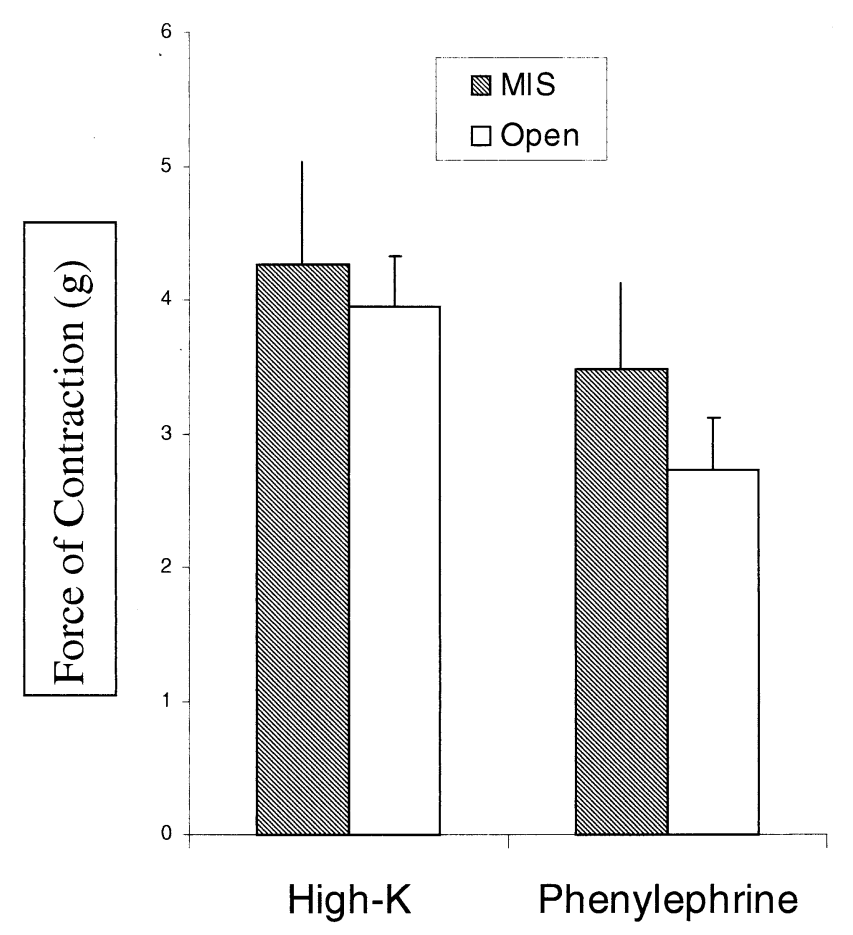

Figure 3. Responses to high- $\mathrm{K}^{+}$and PE. Note that there was a similar force of contraction in response to high- $\mathrm{K}^{+}$in GSV segments from both the MIS (4.26 $\pm 0.72 \mathrm{~g}$, shaded bar) and open $(3.95 \pm 0.38 \mathrm{~g}$, open bar) harvesting groups $(P=.70)$. Similarly, the force of contraction after exposure to PE was similar in GSV segments from both the MIS (3.49 $\pm 0.63 \mathrm{~g}$, shaded bar) and open $(2.73 \pm 0.39 \mathrm{~g}$, open bar) harvesting groups $(P=.41)$.

\section{Composition of Solutions}

Plasma-Lyte contained the following: sodium chloride ( $\mathrm{NaCl}), 526$ $\mathrm{mg} / 1000 \mathrm{~mL}$; sodium gluconate, $502 \mathrm{mg} / 1000 \mathrm{~mL}$; sodium acetate trihydrate, $368 \mathrm{mg} / 1000 \mathrm{~mL}$; potassium chloride $(\mathrm{KCl}), 37 \mathrm{mg}$ / $1000 \mathrm{~mL}$; magnesium chloride hexahydrate, $30 \mathrm{mg} / 1000 \mathrm{~mL}$; and $\mathrm{pH}$ adjusted with sodium hydroxide to 7.4.

RPMI 1640 cell culture medium was prepared as per the instructions provided by the supplier and contained penicillin (5000 U/L) and streptomycin $(5000 \mu \mathrm{g} / \mathrm{L})$.

The ionic composition of the PSS was as follows: $\mathrm{NaCl}, 140$ $\mathrm{mmol} / \mathrm{L} ; \mathrm{KCl}, 5.9 \mathrm{mmol} / \mathrm{L}$; magnesium chloride hexahydrate, 1.2 $\mathrm{mmol} / \mathrm{L}$; calcium chloride dehydrate, $2.5 \mathrm{mmol} / \mathrm{L}$; glucose, 11 $\mathrm{mmol} / \mathrm{L}$; and 4-(2-hydroxyethyl)piperazine-1-ethanesulfonic acid, $10 \mathrm{mmol} / \mathrm{L}$.

For the $80 \mathrm{mmol} / \mathrm{L}$ potassium $\left(\mathrm{K}^{+}\right)$PSS (high-K ${ }^{+}$solution), 75 $\mathrm{mmol} / \mathrm{L} \mathrm{NaCl}$ was replaced with an equimolar amount of $\mathrm{KCl}$.

\section{Drug Dissolution Information}

$\mathrm{PE}$ and $\mathrm{ACh}$ were dissolved in distilled water and frozen in 1-mL aliquots of $0.1,0.1$, and $0.01 \mathrm{~mol} / \mathrm{L}$, respectively. Dilutions were made fresh daily with PSS, and drug additions were always less than or equal to $50 \mu \mathrm{L}$. All stock solutions were prepared in advance and stored at $-20^{\circ} \mathrm{C}$ until use. The vehicles did not affect responses to $\mathrm{PE}, \mathrm{ACh}$, and $80 \mathrm{mmol} / \mathrm{L} \mathrm{K}^{+}$(data not shown).

\section{Materials}

Plasma-Lyte was prepared by Baxter Corp. RPMI 1640 cell culture medium and penicillin-streptomycin were purchased from Canadian Life Technologies. ACh was purchased from Sigma-Aldrich. PE was obtained from Research Biochemicals International.

\section{Results}

As shown in Figure 3, there was no difference between groups in the force of contraction elicited in the undistended GSV in response to high- $\mathrm{K}^{+}$solution.

Similarly, there was no difference between groups in the force of contraction elicited after exposure to $50 \mu \mathrm{mol} / \mathrm{L} \mathrm{PE}$ (Figure 3).

There was, however, a marked difference in the response to ACh between GSV rings from the MIS and open harvesting groups (Figure 4). Note that control responses represented the level of PE-induced force had ACh not been added to the tissue. In MIS tissues ACh responses at both 1 and $10 \mu \mathrm{mol} / \mathrm{L}$ were not significantly different from control responses (ie, no average change in tension from the decay in the plateau phase of contraction after stimulation with 50 $\mu \mathrm{mol} / \mathrm{L} \mathrm{PE}$ ), indicating an absence of normal endothelial function. Furthermore, after exposure to $10 \mu \mathrm{mol} / \mathrm{L} \mathrm{ACh}$, there was a tendency for ACh-mediated contractions to be present, although this was not statistically significant $(P=$ .43). In contrast, $\mathrm{ACh}$ relaxed PE-precontracted rings in undistended GSVs from the open harvesting group $(P=$ .0007 and $P=.004$ for 1 and $10 \mu \mathrm{mol} / \mathrm{L} \mathrm{ACh}$, respectively), demonstrating preservation of endothelial function in GSVs harvested with the open technique.

\section{Discussion}

The pivotal finding of this study is that MIS harvesting of the GSV without the aid of a lighted retractor or endoscopic equipment is associated with impaired endothelium-dependent relaxation compared with that seen in segments isolated by using the conventional open harvesting technique. There was no difference in contractile function between these 2 groups of segments.

In our study we assessed biologic properties of the harvested veins by exposure to (1) a nonspecific vasoconstrictor, high-K $\mathrm{K}^{+}$; (2) a specific vasoconstrictor, the $\alpha_{1}$-adrenergic agonist PE; and (3) a specific endothelium-dependent vasodilator, ACh. A functional method was used to evaluate and compare the viability and quality of the GSV used in CABG operations harvested by means of the MIS and open techniques because the presence of an intact wall, as obtained by means of morphologic studies, does not necessarily imply normal function of the tissue.

In discussing MIS harvesting of the GSV, it is important to first recognize that there are many methods claiming to be minimally invasive. Those methods that should be considered minimally invasive include harvesting through multiple small incisions with the aid of a Mayo stripper, ${ }^{2}$ com- 
pletely endoscopic SV harvesting, ${ }^{9,10}$ and harvesting of the vein with the aid of various lighted retractors. ${ }^{1,9}$ These 3 methods are important in that they have been proved to preserve the endothelium on the basis of formal in vitro testing of relaxation in response to ACh. Furthermore, histologic, electron microscopic, and immunologic testing has been carried out on vein segments harvested by using these methods, demonstrating that the endothelium is physically intact. ${ }^{2,3,10}$ These methods differ from the method described in this article in that they did not involve the application of high traction forces on the vein during harvesting.

The MIS technique of GSV harvesting described in this article was developed primarily as a means of reducing the morbidity associated with the long continuous incision used in the traditional open technique of GSV harvesting without incurring the increased costs of endoscopic equipment or lighted retractors with nonreusable parts. To our knowledge, traction injury has not been previously identified as a cause of endothelial cell trauma or damage in the GSV. The results of this study suggest that the traction forces applied to the GSV during MIS harvesting of the GSV without the aid of a lighted retractor, endoscopic equipment, or Mayo stripper causes endothelial cell dysfunction.

In the last few years, the importance of the endothelium in the regulation of vascular tone and prevention of atherosclerosis has become apparent. ${ }^{12,13}$ As a result, endothelial cell damage has been recognized as a key factor in the development of intimal thickening and atherosclerosis. The normal function of a healthy endothelium serves to prevent vasoconstriction and the development of thrombus. It is now understood that the endothelium is the primary site of the production of NO, a potent vasodilator. Other products of the endothelium include prostacyclin and bradykinin. The combined action of these endothelial cell-derived products is vasodilation, inhibition of platelet aggregation, and prevention of smooth muscle cell proliferation and migration. ${ }^{12,13}$

The endothelium is also a site of production of angiotensin II, endothelin I, and thromboxane A2, all of which cause vasoconstriction, platelet aggregation, and thrombus formation, as well as smooth muscle cell proliferation and migration. When the endothelium is traumatized or dysfunctional, the production of NO is impaired, and the relative production of angiotensin II, endothelin I, and thromboxane A2 is increased, resulting in intimal thickening and, ultimately, atherosclerosis. ${ }^{12,14}$ This result is especially true of the arterial circulation and has also been shown to be important in the pathophysiology of SV graft failure. ${ }^{7,14}$

SV occlusion continues to affect up to $50 \%$ of patients 10 years after CABG surgery. There are multiple mechanisms underlying SV graft failure. ${ }^{7,15,16}$ These include diseases affecting the GSV, such as phlebitis and varicosity, which might affect the quality of the GSV before use during

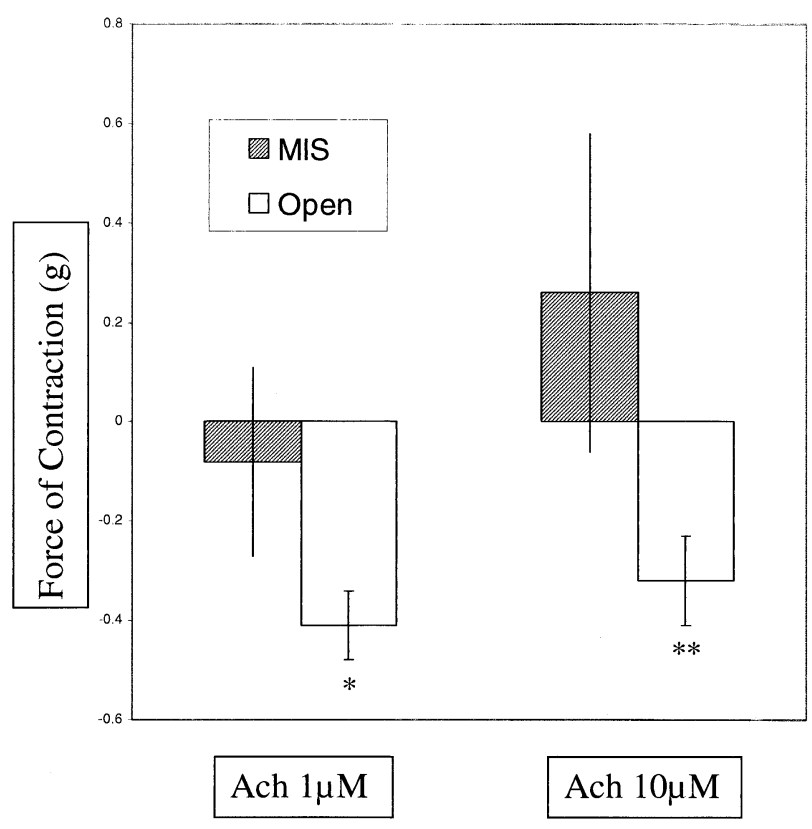

Figure 4. Response to $\mathrm{ACh}$ after precontraction with PE. Responses to both 1 and $10 \mu \mathrm{mol} / \mathrm{L}$ ACh in GSV segments from the MIS (shaded bars) and open (open bars) harvesting groups compared with control (ie, the level of PE-induced force of contraction with exposure to $\mathrm{ACh}$ ) are shown. There was no significant net relaxation after exposure to $1 \mu \mathrm{mol} / \mathrm{L} \mathrm{ACh}$ in GSV segments from the MIS group $(-0.08 \pm 0.19 \mathrm{~g}, P=.66)$, with a net contraction on average after exposure to $10 \mu \mathrm{mol} / \mathrm{L}$ ACh, although this was not statistically significant $(0.26 \pm 0.32 \mathrm{~g}, P=.43)$. In contrast, there were highly significant mean net relaxations of $-0.41 \pm 0.07 \mathrm{~g}$ after exposure to $1 \mu \mathrm{mol} / \mathrm{L} \mathrm{ACh}$ and $-0.32 \pm 0.09 \mathrm{~g}$ after exposure to $10 \mu \mathrm{mol} / \mathrm{L}$ ACh in GSV segments from the open harvesting group $\left({ }^{*} P=.0007\right.$ and ${ }^{*} P=.004$, respectively).

CABG surgery. Exposure of the SV endothelium to the shear stress of arterial flow and pressure is thought to result in endothelial cell damage. ${ }^{16}$ Finally, trauma to the vein during harvesting caused by vein handling has also been shown to result in endothelial trauma and dysfunction. ${ }^{14,17}$

The relationship between endothelial cell function and long-term patency of SV grafts is not clearly established; however, recent studies suggest that preservation of endothelial cell function is important for long-term patency. In one study of GSV harvesting with the aid of a Mayo stripper, GSV segments demonstrated preserved endothelial cell function, and $92 \%$ of vein grafts were patent 1 year after CABG surgery, as determined by means of magnetic resonance angiography. ${ }^{2}$ Another group studied GSV segments harvested with a surrounding pedicle. ${ }^{18,19}$ These segments had greater endothelial cell preservation tested by means of CD31 immunostaining compared with that seen in the segments harvested by means of the traditional open method without a pedicle. ${ }^{19}$ On angiographic follow-up at 18 
months, $95.4 \%$ of vein grafts harvested with a pedicle were patent. This patency rate was comparable with that of left internal thoracic artery grafts $(93.3 \%) .^{18}$

The results of this study must be interpreted with caution. GSV segments normally undergo high-pressure distention after harvesting. However, undistended GSV segments were used in this study because it has been well established that distended vein has markedly reduced vasodilatory capacity because of endothelial disruption. ${ }^{15,17}$ As a result, the clinical implications of using GSV segments from either an open harvesting technique or an MIS technique are unknown when the vein is exposed to high-pressure distention after harvesting. Extrapolations from this study to the in vivo situation must be made with caution. There is only one study using MIS harvesting techniques that included clinical follow-up of vein graft patency after CABG surgery. ${ }^{2}$ Another strategy to preserve endothelial function involves the administration of vasodilator substances to the vein before removal of the vein from the leg to mitigate the vasospasm that occurs during harvesting. For example, the subcutaneous injection of papaverine before incision of the skin has been shown to preserve endothelial function in vein segments. ${ }^{20}$ Papaverine and other vasodilators, such as glyceryl trinitrate and verapamil, might be useful pharmacologic agents that could reduce the need for high-pressure distention of the vein after harvesting. ${ }^{6,20}$ More studies evaluating clinical outcomes are necessary to further evaluate the importance of preservation of endothelial function during MIS harvesting of the SV.

\section{Conclusion}

Normal endothelial cell function of GSV grafts used in CABG surgery is an important determinant of patency up to 18 months postoperatively. Several methods of MIS harvesting of the GSV have demonstrated preservation of endothelial cell function with the use of lighted retractors, the Mayo stripper, and endoscopic equipment. In contrast, MIS harvesting of the GSV through multiple small incisions without the use of specialized equipment requires the application of substantial traction forces on the GSV during harvesting. Testing of GSV segments from vein harvested by using this MIS technique demonstrated abnormal endothelial cell function, as detected by the response to ACh after precontraction with PE. Therefore traction injury during MIS harvesting of the GSV is associated with endothelial dysfunction. Clinical trials are necessary to determine whether the method of GSV harvesting has an effect on long-term patency rates of SV grafts used in CABG surgery.

We thank all the cardiac surgeons for their generous supply of human saphenous vein from the Royal Columbian Hospital and St Paul's Hospital. We are very grateful for the valuable support of the cardiac residents, surgical assistants, and cardiac nursing staff at both institutions. In addition, we are thankful for the help with tissue collection from the Cardiovascular Registry of St Paul's Hospital, directed by Dr Bruce McManus, and for the assistance of Stephanie A. Gin with the experiments.

\section{References}

1. Greenfield GT, Whitworth WA, Tavares LL, Wittenbraker MT, Wallace DM, Valdivia JA, et al. Minimally invasive vein harvest and wound healing using the SaphLITE retractor system. Ann Thorac Surg. 2001;72(suppl):S1046-9.

2. O'Regan DJ, Borland JAA, Chester AH, Pennell DJ, Yacoub M, Pepper JR. Assessment of human long saphenous vein function with minimally invasive harvesting with the Mayo stripper. Eur J Cardiothorac Surg. 1997;12:428-35.

3. Fabricius AM, Diegeler A, Doll N, Weidenbach H, Mohr FW. Minimally invasive saphenous vein harvesting techniques: morphology and postoperative outcome. Ann Thorac Surg. 2000;70:473-8.

4. Furchgott RF, Zawadzki JV. The obligatory role of endothelial cells in the relaxation of arterial smooth muscle by acetylcholine. Nature. 1980;288:373-6

5. Dhein S, Reiss N, Gerwin R, Borowski A, Korb H, Klaus W, et al. Endothelial function and contractility of human vena saphena magna prepared for aortocoronary bypass grafting. Thorac Cardiovasc Surg. 1991;39:66-9.

6. He GW, Rosenfeldt FL, Angus JA. Pharmacological relaxation of the saphenous vein during harvesting for coronary artery bypass grafting. Ann Thorac Surg. 1993;55:1210-7.

7. Angelini GD, Bryan AJ, Williams HMJ, Soyombo AA, Williams A, Tovey J, et al. Time-course of medial and intimal thickening in pig venous arterial grafts: relationship to endothelial injury and cholesterol accumulation. J Thorac Cardiovasc Surg. 1992;103:1093-103.

8. Hozumi T, Yoshikawa J, Yoshida K, Akasaka T, Takagi T, Honda Y, et al. Use of intravascular ultrasound for in vivo assessment of changes in intimal thickness of angiographically normal saphenous vein grafts one year after aortocoronary bypass surgery. Heart. 1996;76:317-20.

9. Fabricius AM, Oser A, Diegeler A, Rauch T, Mohr FW. Endothelial function of human vena saphena magna prepared with different minimally invasive harvesting techniques. Eur J Cardiothorac Surg. 2000; 18:400-3.

10. Cable DG, Dearani JA, Pfeifer EA, Daly RC, Schaff HV. Minimally invasive saphenous vein harvesting: endothelial integrity and early clinical results. Ann Thorac Surg. 1998;66:139-43.

11. Furchgott RF. Role of endothelium in responses of vascular smooth muscle. Circ Res. 1983;53:557-73.

12. Verma S, Anderson TJ. Fundamentals of endothelial function for the clinical cardiologist. Circulation. 2002;105:546-9.

13. Vallance $P$, Chan N. Endothelial function and nitric oxide: clinical relevance. Heart. 2001;85:342-50.

14. Soyombo A, Angelini GD, Bryan AJ, Newby AC. Surgical preparation induces injury and promotes smooth muscle cell proliferation in a culture of human saphenous vein. Cardiovasc Res. 1993;27:1961-7.

15. Sessa C, Morasch MD, Friedland M, Kline RA. Risk factors of atherosclerosis and saphenous vein endothelial function. Int Angiol. 2001;20:152-63.

16. Davies MG, Hagen P-O. Pathophysiology of vein graft failure: a review. Eur J Vasc Endovasc Surg. 1995;9:7-18.

17. Liu Z-G, Liu X-C, Yim APC, He G-W. Direct measurement of nitric oxide release from saphenous vein: abolishment by surgical preparation. Ann Thorac Surg. 2001;71:133-7.

18. Tsui JCS, Souza DSR, Filbey D, Bomfim V, Dashwood MR. Preserved endothelial integrity and nitric oxide synthase in saphenous vein grafts harvested by a "no-touch" technique. Br J Surg. 2001;88:1209-15.

19. Souza DSR, Bomfim V, Skoglund H, Dashwood MR, Borowiec JW, Bodin L, et al. High early patency of saphenous vein graft for coronary artery bypass harvested with surrounding tissue. Ann Thorac Surg. 2001;71:797-800.

20. LoGerfo FW, Haudenschild CC, Quist WC. A clinical technique for prevention of spasm and preservation of endothelium in saphenous vein grafts. Arch Surg. 1984;119:1212-4. 